and brown-OR: 1.1 to 0.9 ; 1.5). These estimates were not significantly altered in models including variables related to life-course SEP. Conclusion In this Brazilian population, UL risk increased with the darkening of skin colour, and the life-course SEP did not mediate this association.

\section{P1-418 PREVALENCE OF DENTAL PAIN AND ASSOCIATED FACTORS AT 5 YEARS OLD: FINDINGS FROM A BRAZILIAN BIRTH COHORT}

doi:10.1136/jech.2011.142976g.8

\begin{abstract}
${ }^{1} \mathrm{~F}$ Demarco, ${ }^{* 1} \mathrm{G}$ Boeira, ${ }^{1} \mathrm{M}$ Correa, ${ }^{2} \mathrm{~K}$ Peres, ${ }^{2} \mathrm{M}$ Peres, ${ }^{1} \mathrm{I}$ Santos, ${ }^{1} \mathrm{~A}$ Matijasevich, ${ }^{1}$ A Barros. ${ }^{1}$ Federal University of Pelotas, Pelotas, Rio Grande do Sul, Brazil, ${ }^{2}$ Federal University of Santa Catarina, Florianopolis, Santa Catarina, Brazil
\end{abstract}

Introduction Despite dental pain being an important public health issue, very few studies have investigated its occurrence in preschool children using a life course approach. The objective of this study was to describe the prevalence of dental pain in preschool children and its association with life course characteristics.

Methods This study was nested in a population-based birth cohort from Pelotas, Brazil, started in 2004. A sample of 1129 children aged 5 years old underwent dental examination and their mothers were interviewed. Exploratory variables included sociodemographic factors, maternal oral health status and associated behaviours, and children's primary dental caries. Data were analysed using multivariable Poisson regression.

Results Toothache was present in $16.5 \%$ of the population in the 6 months prior to interview. Adjusted analyses showed that darkskinned children [Prevalence ratio (PR)=1.6 (95\% CI 1.1 to 2.4)], from low economic level [PR 1.9 (1.2 to 3.0)], whose mothers had $<4$ years of study [PR 1.9 (1.0 to 3.6)], and whose mothers with $<10$ teeth in one arch at least [PR 1.66 (1.09 to 2.53)], and those with high caries prevalence at age 5 years [PR 4.8 (3.3 to 7.1)] were associated with dental pain.

Conclusions Low family income and lack of children's schooling are the main early life risk factors for dental pain in preschool children. Poor maternal and child dental status are associated with dental pain. The socioeconomic and family context in which dental pain occurs should be taken into account when dental pain preventive measures are implemented.

\section{P1-419 HEALTH PROMOTING SCHOOL INITIATIVE IN ASHRAM SCHOOLS OF WARDHA DISTRICT: AN EVALUATION}

doi:10.1136/jech.2011.142976g.9

${ }^{1} \mathrm{~A}$ Dongre, ${ }^{*} \mathrm{P}$ Deshmukh, ${ }^{2} \mathrm{~B}$ Garg. ${ }^{1}$ Department of Community Medicine, Sri Manakula Vinayagar Medical College, Pondicherry, India; ${ }^{2}$ Dr Sushila Nayar School of Public Health, Mahatma Gandhi Institute of Medical Sciences, Sewagram, India

Objective To study the effect of health promoting school-based intervention for disadvantaged children in the residential Ashram Schools of rural Wardha district of central India.

Material and Methods At baseline, 1287 children in 10 Ashram schools were examined using locally adopted Global School-based Student Health Survey questionnaire. Ashram (residential) schools are residential schools providing lodging and boarding, uniforms, books and notebooks and educational equipments to its poor inmates. It covered information on personal hygiene, physical status, nutrition, environment, substance abuse, risk behaviour, life skills and others. Haemoglobin examination of all children was done by using Haemoglobin colour scale. Body Mass Index (BMI) and Physical activity score for each child was calculated. Intervention was carried out through trained school health committee members. After 1 year, 1226 children were examined as end line assessment by using the same questionnaire. The data were entered and analysed using Epi info software.

Results Overall, there was significant improvement in the status personal hygiene and reduction in related morbidities among school children. Noteworthy, percentage of current tobacco consuming children declined significantly from 506 (39.3\%) to 210 (17.1\%). The mean haemoglobin of the children increased from $10.7 \mathrm{~g} / \mathrm{dl}$ to $11.4 \mathrm{~g} /$ dl. Notably, there was significant decline in thin (below $5^{\text {th }}$ percentile) children from $67.5 \%$ to $60.8 \%$ and there is increase in normal children with BMI for age $\left(5^{\text {th }}-85^{\text {th }}\right.$ percentile) from $32.2 \%$ to $38.5 \%$. Conclusions The need based participatory Health Promoting School initiative for vulnerable Ashram school children could improve their health status.

\section{P1-420 FIBRE INTAKE AND EVOLUTION OF BODY MASS INDEX: FROM PREPREGNANCY TO POSTPARTUM}

doi:10.1136/jech.2011.142976g.10

M Drehmer, ${ }^{*}$ S Camey, M A Nunes, B Duncan, M Lacerda, M I Schmidt. Universidade Federal do Rio Grande do Sul, Programa de Pós-Graduação em Epidemiologia, Porto Alegre, Rio Grande do Sul, Brazil

Background Postpartum weight retention is important risk factor for obesity in reproductive age women. The role of fibre intake still needs clarification, being among those dietetic factors that may be associated with a positive evolution of postpartum weight variation. Objectives To evaluate the effect of fibre intake on the evolution of maternal body mass index (BMI) from pregnancy to postpartum, and to identify dietary patterns associated with fibre intake.

Methods A cohort of 370 pregnant women was followed until the sixth month of postpartum. Food intake was obtained using foodfrequency questionnaire. Focused principal component analysis was used centered on postpartum weight retention and on total dietary fibre intake. Obesity risk was a variable defined to indicate unfavourable evolution of BMI in postpartum. Poisson regression was used to estimate the association between fibre intake and obesity risk.

Results Participants retained a median of $4.4 \mathrm{~kg}$ (IR 0.6; 7.9), and obesity risk was present in $55.1 \%(n=189)$ of the sample. Individual food items did not have an important effect on weight retention. The highest contribution of fibre intake came from the consumption of beans. Consumption of bread and rice indicated a common Brazilian food pattern along with beans. In the multivariable model, inadequate fibre intake increased $24 \%$ (95\% CI 1.05 to 1.47$)$ the obesity risk, after adjusting for maternal age, prepregnancy BMI and total gestational weight gain.

Conclusion Maternal BMI showed an increasing trend from prepregnancy to postpartum. Adequate fibre intake may reduce obesity risk in the period following childbirth.

\section{P1-421 DETERMINANTS OF SATISFACTION WITH HEALTHCARE: A POPULATION-BASED STUDY FROM IRAN}

doi:10.1136/jech.2011.142976g.11

F Farzadi, A Montazeri, ${ }^{*}$ J Sadighi, S Omidvari, F Maftoon, A Aeenparast, K Jahangiri, M Vahdaninia. Iranian Institute for Health Sciences Research, ACECR, Tehran, Iran

Introduction Satisfaction with healthcare is an important indicator of effective healthcare delivery. It could contribute to both policy and practice.

Methods This was a nationwide cross sectional study. A random sample of individuals aged between 18 and 65 were entered into study. Respondents were asked to rate their overall satisfaction with healthcare on a 5-point scale. The record of demographic and socioeconomic data included age, gender, education, marital status, employment, income, and chronic diseases. Logistic regression 
analysis was used to estimate ORs for factors contributing to satisfaction with healthcare.

Results In all 27883 individuals were studied. The mean age of respondents was $32.7(\mathrm{SD}=11.8)$ years. In all $20.7 \%$ of the respondents were satisfied or very satisfied with healthcare delivery while $36.2 \%$ of people indicated little or no satisfaction with healthcare. The results obtained from regression analysis indicated that income (a proxy measure of access to healthcare) and information was the most significant contributing factor to people's dissatisfaction [OR for lower income $=2.17, \mathrm{p}<0.0001$; $O R$ for people with poor health information $=2.01, \mathrm{p}<0.001]$.

Conclusion The study findings suggest that improving access to information and healthcare could lead to people's satisfaction with healthcare.

\section{P1-422 ACCURACY AND QUALITY OF ROUTINE IMMUNISATION DATA MONITORING SYSTEM IN OGBARU AND ONITSHA NORTH LOCAL GOVERNMENT AREAS OF ANAMBRA STATE, NIGERIA}

doi:10.1136/jech.2011.142976g.12

A Fatiregun, ${ }^{*}$ C Awogu. College of Medicine, University of Ibadan, Ibadan, Oyo State, Nigeria

Immunisation managers often depend on immunisation coverage obtained from immunisation data monitoring system to guide planning. However, limited studies have been carried out to verify the accuracy or determine the quality of the immunisation information system at the Health Facilities (HFs) and Local Government Areas (LGAs), which are the sources of the data reported to the state and national levels. This study was to assess the quality and accuracy of immunisation data in Ogbaru (OGB) and Onitsha North (ONN) LGAs of Anambra State, Nigeria. A WHO validated methodology of immunisation Data Quality Audit was used. All the HFs conducting immunisation in OGB (28) and ONN (20) as well as the two LGAs' Immunisation Units (IUs) were visited. The records of DPT3 immunisation at the HFs from January to December, 2009 was recounted and compared with reported data at the LGA IUs for the same period. An Accuracy Ratio (AR) which expresses the ratio of immunisation recounted at the HFs to that reported to the LGAs IUs was obtained. AR of $\geq 0.95$ to $\leq 1.05$ indicates data consistency. Immunisation Focal Persons (IFPs) in each HFs were interviewed using a validated tool that contained a 70 point knowledge scale and a 120 item quality score (OS) on data monitoring system. The proportion of HFs with consistent data were $27.6 \%$ and $42.9 \%(p<0.05)$ in $\mathrm{OGB}$ and $\mathrm{ONN}$ respectively. The overall AR was $89.8 \%$ in OGB and $96.3 \%$ in ONN. The mean knowledge score among IFPs in the LGAs was $44.0 \pm 8.0$ and $46.2 \pm 6.9(p<0.05)$, while the mean OS for HFs was $74.5 \pm 18.0$ and $73.6 \pm 13.2$ in OGB and ONN respectively $(p<0.05)$. There was a fair correlation between the overall $\mathrm{QS}$ and the overall knowledge score in the two LGAs, $r=0.3(p>0.05)$. Auditing showed inconsistent data and low quality of data reporting in the LGAs.

\section{P1-423 ASSESSMENT OF INFLUENZA OUTBREAKS USING A PRIVATE HEALTHCARE INFORMATION SYSTEM: AN ANALYSIS OF THE 2009 H1N1 EPIDEMIC IN BUENOS AIRES}

doi:10.1136/jech.2011.142976g.13

S Figar, * V Aliperti, V Taliercio, C Otero, E Salazar, M Schpilberg, P Otero, F G B de Quirós. Hospital Italiano de Bunos Aires, Buenos Aires, Argentina

Introduction This study aims to determine if the A/H1N1 influenza outbreak could have been earlier detected through changes in morbidity and mortality patterns analysed from a health information system (HIS).
Methods Specific data subsets were created to compare the burden of influenza during the epidemiological week (EW) 21 to 26 for years 2007 to 2009 among 150000 Health Maintenance Organization members in Buenos Aires. The threshold for identifying an epidemic was considered met when the weekly influenza-like illness (ILI) rate exceeded 200 per 100 visits. Mortality rates of severe acute respiratory infection (SARI) from 2007 to 2009 were compared. Case fatality and mortality rates for A/H1N1 influenza 2009 also were estimated.

Results The HIS detected the outbreak in EW 23 while the government Ministry of Health $(\mathrm{MoH})$ gave a national epidemic alert during EW 25. The number of visits for ILI increased more than fourfold when comparing 2009 to the 2007-2008. SARI mortality rate in 2009 was higher than in 2008 (RR 2.8; 95\% CI 1.18 to 6.63) and similar to that of 2007 (RR 1.05; 95\% CI 0.56 to 1.49). 2009 was the first year with mortalities younger than 65 years attributable to SARI. The estimated $\mathrm{A} / \mathrm{H} 1 \mathrm{~N} 1$ case fatality rate for SARI was $6.2 \%$ (95\% CI 2.5 to 15.5 ). The estimated A/H1N1 mortality rate was 6 per 100000 (95\% CI 0 to 11.6).

Conclusions the outbreak was detected 2 weeks before than the $\mathrm{MoH}$ gave a national alert suggesting that with a private-public integration a more real-time outbreak and disease surveillance system could be implemented.

\section{P1-424 LIFETIME SCHOOL FAILURE AND PHYSICAL FIGHTING AT 17 YEARS OF AGE}

doi:10.1136/jech.2011.142976g.14

${ }^{1,2} \mathrm{~S}$ Fraga, ${ }^{* 1,2} \mathrm{E}$ Ramos, ${ }^{1,2} \mathrm{H}$ Barros. ${ }^{1}$ Institute of Public Health, University of Porto, Porto, Portugal; ${ }^{2}$ Department of Hygiene and Epidemiology, University of Porto Medical School, Porto, Portugal

Objective To evaluate the association between school grade retention and physical fighting among adolescents.

Methods We evaluated 1687 adolescents, part of EPITeen population-based cohort of urban adolescents, at 13 and 17 years of age. At both study waves, socio-demographic and behavioural characteristics were obtained by self-completed questionnaires. School failure was considered as the school grades retention reported by adolescents. Physical fighting was only assessed at 17 years-old, and participants were asked "During the past 12 months, were you involved in a physical fight?" ORs and 95\% CIs were estimated separately for girls and for boys.

Results $28.2 \%$ of the girls who had school grade retention after 13 years old and $33.5 \%$ who had school retention before 13 years old reported involvement in physical fighting. For boys, the respective frequencies were $49.4 \%$ and $61.7 \%$. After adjustment for potential confounders in a stepwise model, the odds for involvement in fights were $2.45(1.50-3.99)$ in girls and $1.38(0.90-2.12)$ in boys when considering school grade retention that occurred only after 13 years old. Considering those with school grade retention before 13 years old, the association was even stronger: 2.75 (1.64-4.59) in girls and $2.52(1.63-3.89)$ in boys.

Conclusion School failure increased the risk of physical fighting involvement among adolescents; school retention during compulsory school phase (until 13 years old) seems even more relevant.

\section{P1-425 RISK FACTORS FOR OVERWEIGHT AND OBESITY IN PRE- SCHOOL CHILDREN}

doi:10.1136/jech.2011.142976g.15

${ }^{1,2} \mathrm{~V}$ Kaufman-Shriqui, ${ }^{1,2} \mathrm{D}$ S. Shahar, ${ }^{1,2} \mathrm{D}$ Fraser. ${ }^{1}$ Ben-Gurion University of the Negev, Beer-Sheva, Israel; ${ }^{2}$ Intl. Center for Health \& Nutrition, BGU, Beer-Sheva, Israel

Introduction In 2008 the prevalence of obesity in the USA, England and Italy were $14.6 \%, 21.2 \%$ and $22.2 \%$, respectively. Childhood 